\title{
Improvement of Physiological Active Substance of Wheat Dried Distillers' Grains with Solubles Fermented by Preussia aemulans under Optimum Fermentation Conditions
}

\author{
Yiting $\mathrm{Li}^{1}$, Honghai $\mathrm{Hu}^{2}$, Xiaoyan $\mathrm{Zu}^{3}$, Min $\mathrm{Shi}^{1}$, Zhenya Zhang ${ }^{1} \&$ Yingnan Yang ${ }^{1}$ \\ ${ }^{1}$ Graduate School of Life and Environmental Sciences, University of Tsukuba, Ibaraki, Japan \\ ${ }^{2}$ Food Science Department, Ishikawa Prefectural University, Suematsu, Nonoichi, Ishikawa, Japan \\ ${ }^{3}$ Institute for Farm Products Processing and Nuclear-Agriculture Technology, Hubei Academy of Agricultural \\ Sciences, Wuhan, China \\ Correspondence: YingnanYang, Graduate School of Life and Environmental Sciences, University of Tsukuba, \\ Ibaraki 305-8577, Japan. Tel: 81-29-853-4650. E-mail: yo.innan.fu@u.tsukuba.ac.jp
}

Received: August 16, 2012 Accepted: September 7, 2012 Online Published: September 21, 2012

doi:10.5539/ijb.v4n4p91

URL: http://dx.doi.org/10.5539/ijb.v4n4p91

\begin{abstract}
In this study, a new fungus named Preussia aemulans was isolate from Cordyceps sinensis fruiting body. The agricultural waste of wheat dried distillers' grains with solubles (DDGS) was utilized as a culture medium for Preussia aemulans. By using orthogonal experiment, the fermentation conditions of polysaccharide, polyphenol and adenosine were optimized. Under the optimum fermentation conditions of polysaccharide, polyphenol and adenosine, the content of polysaccharide, polyphenol, adenosine and protein were $32.68 \pm 3.24 \mathrm{mg} / \mathrm{g}$ dry matter, $7.91 \pm 0.2 \mathrm{mg} / \mathrm{g}$ dry matter, $1.36 \pm 0.24 \mu \mathrm{mol} / \mathrm{g}$ dry matter and $104.41 \pm 6.65 \mathrm{mg} / \mathrm{g}$ dry matter, respectively. Based on the nutritional profile, the fermented wheat DDGS could be utilized as functional material of feed or food.
\end{abstract}

Keywords: Cordyceps sinensis, wheat dried distillers' grains with solubles (DDGS), Preussia aemulans, Fermentation

\section{Introduction}

Cordyceps, one of the well-known traditional Chinese medicines is a large family which contains more than 350 types of fungi, such as Cordyceps militaris, Cordyceps ophioglossoides, Cordyceps pseudomilitaris, etc. (Russell, \& Paterson, 2008). Cordyceps sinensis (Berk.) Sacc. is a parasitic fungus and has long been used to treat multitude of ailments, promote longevity, increase athletic power and improve quality of life. The physiological activators of Cordyceps sinensis have been detected, including adenosine, cordycepin, cordycepic acid, d-mannitol, polysaccharides, vitamins and trace elements, etc. (Kumara et al., 2011). Furthermore, according to previous researches, 572 species fungi (Preussia intermedia, Penicillium boreae etc.) were isolated from different parts (stromata, sclerotia, and external mycelial cortices) of natural Cordyceps sinensis fruiting body, and all of the isolated fungus had the similar metabolites and exhibited the similar pharmacological activities as Cordyceps sinensis (Zhang et al., 2010).

In recent years, many herbs and mushrooms have been reported to contain polysaccharides, polyphenol, adenosine with a variety of biological activities. (Zhang, Cui, Cheung, \& Wang, 2007). It has been also reported that polysaccharides extracted from Cordyceps sinensis exhibited many bioactivities, such as antioxidative and anti-tumour activities, and regulating immune functions (Chen, Zhang, Shen, \& Wang, 2010). Polyphenol is a large group, contains various compounds, such as flavonoids, lignans and tannins, etc. Polyphenol was frequently used as natural antioxidant in previous researches (Bhanja, Kumari, \& Banerjee, 2008; Pyoa, Leeb, Logendrac, \& Rosen, 2004; Soong \& Barlow, 2004). Adenosine is an endogenous purine nucleoside that modulates many physiological processes. And it has been used as a marker for the quality control of Cordyceps sinensis in Chinese Pharmacopoeia (Li, Yang, \& Tsim, 2006). Adenosine is known to depress the excitability of central nervous system neurons and to inhibit release of various neurotransmitters presynaptically (Corradetti, Conte, Moroni, Passani, \& Pepeu, 1984). Cordycepin (3'-deoxyadenosine), the important bioactive component in fungi of the genus Cordyceps, was first isolated from the culture filtrates of Cordyceps militaries. And several 
biological activities of cordycepin were reported, such as inhibition of DNA and RNA synthesis, antitumor activity and enhancement of cell differentiation, etc. (Sun, Ling, Lu, \& Zhang, 2003).

Wheat dried distillers' grains with solubles (DDGS); the by-product of ethanol factory has increased in recent years. In Japan, 0.8 million tons of wheat DDGS is disposed every year, and most of wheat DDGS was dumped into ocean or burned. However, according to the London Convention, the ocean disposal was prohibited since 1996. Because of the high content of protein, fiber and reduced starch (Cozannet et al., 2010; Widyaratne \& Zijlstra, 2007), the wheat DDGS has been primarily utilized in ruminant diets (Greter, Penner, Davis, \& Oba, 2008; Penner, Yu, \& Christensen, 2009). Furthermore, based on the nutritional profile, it was considered that the wheat DDGS could be used as a culture medium to culture microbial.

In this study, the wheat DDGS was used as a culture medium for Preussia aemulans (P. aemulans) which was isolated from Cordyceps sinensis fruiting body. The optimum fermentation conditions of polysaccharide, polyphenol and adenosine were investigated, and the nutritional value was detected.

\section{Materials and Methods}

\subsection{Chemicals and Reagents}

D-glucose, sucrose, peptone, $\mathrm{KH}_{2} \mathrm{PO}_{4}, \mathrm{MgSO}_{4}, \mathrm{Na}_{2} \mathrm{CO}_{3}, \mathrm{NaOH}$, potato extract, yeast extract, agar, ethanol, sulfuric acid, phenol, trichloroacetic acid (TCA) and Protein Quantification Kit-Rapid were obtained from Wako Pure Chemical Industries, Ltd, Osaka, Japan. Folin-Ciocalteu's phenol Reagent, Gallic acid, adenosine and cordycepin were purchased from Sigma Aldrich, Inc. (Saint Louis, MO, USA). All other chemical reagents were of analytical grade.

\subsection{Isolation and Cultivation of P. aemulans}

The fruiting body of Cordyceps sinensis was purchased from Qinhai, China, and the isolated P. aemulans mycelium (SIID11759-01) was identified by TechnoSuruga laboratory co., ltd, Japan. The stroma of Cordyceps sinensis fruiting body was sterilized with ethanol three times, air-dried, cut into small segment and transferred to slant tube fermentor to incubate for 7 days, at room temperature.

The white mycelium appeared on the surface during slant fermentation. Then, mycelium was transferred to agar medium, which contained (per liter): $20 \mathrm{~g}$ of surcose, $10 \mathrm{~g}$ of peptone, $20 \mathrm{~g}$ of agar powder, $1.5 \mathrm{~g}$ of $\mathrm{MgSO}_{4}, 3 \mathrm{~g}$ of $\mathrm{KH}_{2} \mathrm{PO}_{4}$. After 7 days of the culture, when white mycelium appeared on the surface of the medium, the mycelium was transferred into the liquid medium, which was containing (per liter): $20 \mathrm{~g}$ of surcose, $10 \mathrm{~g}$ of peptone, $4 \mathrm{~g}$ of potato powder, $1.5 \mathrm{~g}$ of $\mathrm{MgSO}_{4}, 3 \mathrm{~g}$ of $\mathrm{KH}_{2} \mathrm{PO}_{4}$. The Cordyceps sinensis mycelium was incubated in a $200 \mathrm{~mL}$ of flask with $100 \mathrm{~mL}$ of PDA liquid medium, and the mixture was stationary cultured for 7 days.

\subsection{Orthogonal Experiment}

The wheat DDGS was obtained from Kyushu, Japan. The carbon nitrogen ratio and $\mathrm{pH}$ of wheat DDGS were 11.79 and $4.03 \pm 0.02$ respectively. The culture medium was contained $5 \mathrm{~g}$ of wheat DDGS and $100 \mathrm{~mL}$ of distilled water. The adding dosage of sucrose, $\mathrm{pH}$, the fermentation time and the shaking condition were regarded as correlated factors of the fermentation conditions. And the inoculum size of $P$. aemulans was $5 \%$ $(\mathrm{v} / \mathrm{v})$. The optimum fermentation conditions of polysaccharide, polyphenol and adenosine were obtained by an orthogonal layout $\mathrm{L}_{9}\left(3^{4}\right)$. The levels of the factors were shown in Table 1 . After the fermentation, the yield of mycelium was different among the nine experiments, the brown mixture of fermented wheat DDGS and the mycelium was dried $\left(40^{\circ} \mathrm{C}\right)$ and grounded to powder for the further analysis.

Table $1 . \mathrm{L}_{9}\left(3^{4}\right)$ orthogonal design of wheat DDGS by P. aemulans

\begin{tabular}{rcccc} 
Factor & $\begin{array}{c}\text { Adding dosage of sucrose } \\
(\text { ADS })\end{array}$ & $\begin{array}{c}\mathrm{pH} \text { value } \\
(\mathrm{PV})\end{array}$ & $\begin{array}{c}\text { Fermentation time } \\
(\mathrm{FT})\end{array}$ & $\begin{array}{c}\text { Shaking condition } \\
(\mathrm{SC})\end{array}$ \\
\hline 1 & 1 & 6 & 10 & $\begin{array}{c}\text { (day) } \\
(\text { lound } / \mathrm{min})\end{array}$ \\
2 & 2 & 7 & 15 & 0 \\
3 & 3 & 8 & 20 & 100 \\
\hline
\end{tabular}




\subsection{Determination of the Polysaccharide Content}

The polysaccharide content was measured by modified phenol-sulfuric acid method according to Masuko, et al., (2005). The fermented wheat DDGS powder was extracted by boiling water for 2 hours. After filtration, the supernatant was precipitate by $87.5 \%$ of ethanol at $4{ }^{\circ} \mathrm{C}$ for 12 hours. Then, the supernatant was centrifuged at $9500 \mathrm{rpm}$ for $10 \mathrm{~min}$. The precipitate was washed twice by $99.5 \%$ of ethanol and dried at room temperature to remove residual ethanol. Then, the precipitate was dissolved in distilled water and used for polysaccharide analysis. The color reaction was initiated by mixing $1 \mathrm{~mL}$ of crude polysaccharide solution with $0.5 \mathrm{~mL}$ of phenol solution and $2.5 \mathrm{~mL}$ of concentrated sulfuric acid, and the reaction mixture was kept in a $100^{\circ} \mathrm{C}$ water bath for $15 \mathrm{~min}$. After cooling its temperature to room temperature, the optical density (OD) of the mixture was determined at $490 \mathrm{~nm}$ and the crude exopolysaccharide content was calculated with D-glucose as the standard.

\subsection{Determination of Polyphenol Content}

The polyphenol content of the fermented wheat DDGS powder was estimated according to Folin-Ciocalteu, colorimetric method with some modifications (Mau, Lin, \& Song, 2002). The fermented wheat DDGS powder was extracted by methanol for 24 hours in a shaking incubator at ambient temperature. After filtration, the supernatant $(0.5 \mathrm{~mL})$ was mixed with $0.5 \mathrm{~mL}$ of the Folin-Ciocalteu reagent. Three minutes later, $0.5 \mathrm{~mL}$ of $20 \%$ $\mathrm{Na}_{2} \mathrm{CO}_{3}$ was added, and the mixture was made up to $5 \mathrm{~mL}$ with distilled water. After being kept it in dark for 90 $\mathrm{min}$, the OD of the mixture was measured at $725 \mathrm{~nm}$. The polyphenol content was calculated with gallic acid as the standard, and expressed as milligram gallic acid equivalent (mg GAE/g extract).

\subsection{Determination of Adenosine and Cordcepin Contents}

According to Ikeda, Nishimura, Sun, Wada and Nakashima (2008), the adenosine and cordycepin content were simultaneously determined in this experiment with some modifications. The fermented wheat DDGS powder was extracted with deionized water $(1 / 10 \mathrm{~W} / \mathrm{V})$ by using ultrasonic-assisted extract method for $1 \mathrm{~h}(50 \mathrm{~W})$ at ambient temperature. Then, the supernatant was collected and filtered by filter $(0.45 \mu \mathrm{m}$, whatman $)$ for HPLC determination. The samples were analyzed by the HPLC with Capcell-Pak $\mathrm{C}_{18}$ column (4.6 mm I.D. $\times 150 \mathrm{~mm}$, particle size of $5 \mu \mathrm{m}$ ) in a flow rate of $1.0 \mathrm{~mL} / \mathrm{min}$, the column temperature was set at $30^{\circ} \mathrm{C}$ and the $\mathrm{UV}$ detection was operated at $260 \mathrm{~nm}$. The mobile phase was a mixture of acetonitrile and water $(5: 95, \mathrm{v} / \mathrm{v})$.

\subsection{Determination of Protein Content}

The protein content was determined by the Protein Quantification Kit-Rapid (Shi, Yang, Li, Wang, \& Zhang, 2011). Briefly, $200 \mathrm{mg}$ of the fermented wheat DDGS powder was mixed with $4 \mathrm{~mL}$ of phosphate buffer (pH: 7.6) and kept homogenate by pulp refiner for $2 \mathrm{~min}$. After $10 \mathrm{~min}, 6 \mu \mathrm{L}$ of samples $(10 \mathrm{mg} / \mathrm{mL})$ and $300 \mu \mathrm{L}$ of Coomassie Brilliant Blue (CBB) were added into a 96-well plate separately, then the OD of the mixture was measured at $595 \mathrm{~nm}$ and the protein content was calculated by a Bovine serum albumin (BSA) solution as the standard.

\subsection{Determination of Free Amino Acid}

The method of determining free amino acid was according to Shi, Yang, Guan, Wang and Zhang (2012) with some modifications. The fermented wheat DDGS powder was extracted by $80 \%$ ethanol in $80^{\circ} \mathrm{C}$ water bath for $20 \mathrm{~min}$. The supernatant was collected. After repeated the previous steps twice, the sediment was washed by $80 \%$ ethanol. Then all of the collected supernatant was centrifuged and filtered. The supernatant was evaporated to dryness and dissolved with distilled water, then keeping at $4^{\circ} \mathrm{C}$ for $12 \mathrm{~h}$. The solution was mixed with TCA solution at the ratio of $4: 1$ and placing at $4^{\circ} \mathrm{C}$ for $10 \mathrm{~min}$. The $\mathrm{pH}$ was adjusted with $\mathrm{NaOH}$ and $\mathrm{HCl}$ at the range of 2-3. Finally the supernatant was filtered by $0.45 \mu \mathrm{m}$ filter and assessed by an auto amino acid analyzer (JLC -500/V2, Jeol Ltd., Tokyo, Japan) in Chemical Analysis Center (university of Tsukuba).

\subsection{Statistical Analysis}

The obtained data were analyzed by student's t-test, and results were expressed as mean $\pm \mathrm{SD}$. Statistic difference was considered to be significant at $\mathrm{p}<0.01(* *)$.

\section{Results and Discussion}

\subsection{Orthogonal Experiment}

\subsubsection{The yield of polysaccharide}

The polysaccharide yield of the fermented wheat DDGS was shown in Table 2. The highest yield of polysaccharide in the orthogonal experiment was $31.45 \pm 2.46 \mathrm{mg} / \mathrm{g}$ dry matter. The optimum Levels of factors were $3 \%$ adding dosage of the surcose (ADS 3), 10 days of the fermentation time (FT 1), 8 of pH (PV 3), 50 
round/min of shaking condition (SC 2), respectively. The $R$ value of various factors indicated that the adding dosage of the surcose $(3 \%)$ was the highest among these factors. And the significant levels were shown in Table 3 , the results were indicated that all of the factors significantly related with the yield of polysaccharide. Further, the ADS 3, FT 1, PV 3 and SC 2 conditions were demonstrated, the mean polysaccharide content of the fermented wheat DDGS was reached to $32.68 \pm 3.24 \mathrm{mg} / \mathrm{g}$ dry matter. Compared with the polysaccharide content of the unfermented wheat DDGS $(2.23 \pm 0.15 \mathrm{mg} / \mathrm{g}$ dry matter $)$, the polysaccharide content of optimum fermentation conditions (PSOFC) was increased 14 folds during the fermentation by $P$. aemulans.

Table 2. $\mathrm{L}_{9}\left(3^{4}\right)$ orthogonal experiment results of polysaccharide content

\begin{tabular}{cccccc}
\hline $\begin{array}{c}\text { Experimental } \\
\text { group }\end{array}$ & ADS & FT & PV & SC & $\begin{array}{c}\text { Polysaccharide content } \\
(\mathrm{mg} / \mathrm{g} \text { dry matter })\end{array}$ \\
\cline { 2 - 6 } Level & \multicolumn{5}{c}{. } \\
\hline 1 & 1 & 1 & 1 & 1 & $2.82 \pm 0.37$ \\
2 & 1 & 2 & 2 & 2 & $5.68 \pm 0.75$ \\
3 & 1 & 3 & 3 & 3 & $2.93 \pm 0.59$ \\
4 & 2 & 1 & 2 & 3 & $11.67 \pm 1.38$ \\
5 & 2 & 2 & 3 & 1 & $9.41 \pm 1.33$ \\
6 & 2 & 3 & 1 & 2 & $10.43 \pm 1.67$ \\
7 & 3 & 1 & 3 & 2 & $31.45 \pm 2.46$ \\
8 & 3 & 2 & 1 & 3 & $7.32 \pm 1.16$ \\
9 & 3 & 3 & 2 & 1 & $11.61 \pm 0.89$ \\
$\mathrm{I}_{\mathrm{j}}$ & 34.30 & 137.84 & 61.71 & 71.52 & \\
$\mathrm{II}_{\mathrm{j}}$ & 94.54 & 67.23 & 86.90 & 142.70 & \\
$\mathrm{III}_{\mathrm{j}}$ & 151.14 & 74.92 & 131.38 & 65.76 & \\
$R$ & 116.84 & 69.77 & 69.67 & 76.94 & \\
Optimum & 3 & 1 & 3 & 2 & \\
Level & & & & & \\
\hline Add & & & & & \\
\hline
\end{tabular}

Note 1: ADS, Adding dosage of sucrose; FT, Fermentation time; SC, Shaking condition, respectively. Mean values were mean of three determinations with standard deviation $( \pm) . \mathrm{I}_{\mathrm{j}}, \mathrm{II}_{\mathrm{j}}$, III $\mathrm{j}$, were the polysaccharide contents of level 1, level 2 and level 3, respectively; $R$ means the maximum of $\mathrm{I}_{\mathrm{j}}, \mathrm{II}_{\mathrm{j}}$ and $\mathrm{III}_{\mathrm{j}}$ minus the minimum of $\mathrm{I}_{\mathrm{j}}$, $\mathrm{II}_{\mathrm{j}}$ and $\mathrm{III}_{\mathrm{j}}$, respectively.

Table 3. The variance analysis of $\mathrm{L}_{9}\left(3^{4}\right)$ orthogonal test of polysaccharide content

\begin{tabular}{cccccc}
\hline Factor & $\begin{array}{c}\text { Sum of square deviation } \\
(\mathrm{SS})\end{array}$ & $\begin{array}{c}\text { Degree of freedom } \\
(v)\end{array}$ & $\begin{array}{c}\text { Mean square } \\
(\mathrm{MS})\end{array}$ & $F$ ratio & Significance level \\
\hline ADS & 758.66 & 2 & 379.33 & 151.63 & $* * *$ \\
FT & 276.55 & 2 & 138.28 & 55.27 & $* * *$ \\
PV & 333.51 & 2 & 166.76 & 66.66 & $* * *$ \\
SC & 408.09 & 2 & 204.05 & 81.56 & $* * *$ \\
e & 45.03 & 18 & 2.50 & & \\
\hline
\end{tabular}

Note $2: F 0.10(2,18)=2.78 ; F 0.05(2,18)=3.55 ; F 0.01(2,18)=6.01 ; * F$ ratio $>F 0.1 ; * * F 0.01>F$ ratio $>F 0.05 ; * * * F$ ratio $>F 0.01$; ADS, Adding dosage of sucrose; FT, Fermentation time; PV, pH value; SC, Shaking condition, respectively; e, error. 


\subsubsection{The yield of Polyphenol}

As shown in Table 4, the highest mean yield of polyphenol was $8.81 \pm 0.46 \mathrm{mg} / \mathrm{g}$ dry matter, and the optimum Levels of factors were $3 \%$ adding dosage of the surcose (ADS 3), 15 days of the fermentation time (FT 2), 6 of $\mathrm{pH}$ (PV 1), 50 round/min of shaking condition (SC 2), respectively. The $R$ value of various factors indicated that the fermentation time ( 15 days) was the highest among these factors. And the significant levels were shown in Table 5, the results were indicated that the polyphenol content of the fermented wheat DDGS was significantly related to the $\mathrm{pH}$, shaking condition and the fermentation time. The adding dosage of surcose exhibited little influence on the polyphenol content. Further, the ADS 3, FT 2, PV 1 and SC 2 conditions were demonstrated, the mean polyphenol content of the fermented wheat DDGS was reached to $9.46 \pm 0.34 \mathrm{mg} / \mathrm{g}$ dry matter. Compared with the polyphenol content of unfermented wheat DDGS $(1.71 \pm 0.06 \mathrm{mg} / \mathrm{g}$ dry matter), the polyphenol content of optimum fermentation conditions (PPOFC) was increased 6 folds by $P$. aemulans.

Table 4. $\mathrm{L}_{9}\left(3^{4}\right)$ orthogonal experiment results of polyphenol content

\begin{tabular}{cccccc}
\hline $\begin{array}{c}\text { Experimental } \\
\text { group }\end{array}$ & ADS & FT & PV & SC & $\begin{array}{c}\text { Polyphenol content } \\
\text { (mg/g dry matter })\end{array}$ \\
\cline { 2 - 6 } Level & \multicolumn{5}{c}{. } \\
\hline 1 & 1 & 1 & 1 & 1 & $7.20 \pm 0.14$ \\
2 & 1 & 2 & 2 & 2 & $7.99 \pm 0.58$ \\
3 & 1 & 3 & 3 & 3 & $6.86 \pm 0.89$ \\
4 & 2 & 1 & 2 & 3 & $7.55 \pm 0.79$ \\
5 & 2 & 2 & 3 & 1 & $7.38 \pm 0.64$ \\
6 & 2 & 3 & 1 & 2 & $7.99 \pm 0.36$ \\
7 & 3 & 1 & 3 & 2 & $7.91 \pm 0.20$ \\
8 & 3 & 2 & 1 & 3 & $8.81 \pm 0.46$ \\
9 & 3 & 3 & 2 & 1 & $7.07 \pm 0.28$ \\
$\mathrm{I}_{\mathrm{j}}$ & 66.12 & 67.97 & 71.97 & 64.95 & \\
$\mathrm{II}_{\mathrm{j}}$ & 68.76 & 72.52 & 67.82 & 71.64 & \\
$\mathrm{III}_{\mathrm{j}}$ & 71.34 & 65.73 & 66.43 & 69.64 & \\
$R$ & 5.22 & 6.79 & 5.54 & 6.69 & \\
Optimum & 3 & 2 & 1 & 2 & \\
Level & & & &
\end{tabular}

Note 3: ADS, Adding dosage of sucrose; FT, Fermentation time; PV, $\mathrm{pH}$ value; SC, Shaking condition, respectively. Mean values were mean of three determinations with standard deviation $( \pm)$. $\mathrm{I}_{\mathrm{j}}, \mathrm{II}_{\mathrm{j}}$, $\mathrm{III}_{\mathrm{j}}$, were the polyphenol contents of level 1, level 2 and level 3, respectively; $R$ means the maximum of $\mathrm{I}_{\mathrm{j}}, \mathrm{II}_{\mathrm{j}}$ and $\mathrm{III}_{\mathrm{j}}$ minus the minimum of $\mathrm{I}_{\mathrm{j}}$, $\mathrm{II}_{\mathrm{j}}$ and $\mathrm{III}_{\mathrm{j}}$, respectively.

Table 5. The variance analysis of $\mathrm{L}_{9}\left(3^{4}\right)$ orthogonal test of polyphenol content

\begin{tabular}{cccccc}
\hline Factor & $\begin{array}{c}\text { Sum of square deviation } \\
(\mathrm{SS})\end{array}$ & $\begin{array}{c}\text { Degree of freedom } \\
(v)\end{array}$ & $\begin{array}{c}\text { Mean square } \\
(\mathrm{MS})\end{array}$ & $F$ ratio & Significance level \\
\hline ADS & 1.51 & 2 & 0.75 & 2.58 & $*$ \\
FT & 1.85 & 2 & 0.92 & 3.15 & $* *$ \\
PV & 2.66 & 2 & 1.33 & 4.54 & $* *$ \\
SC & 2.62 & 2 & 1.31 & 4.48 & \\
e & 5.27 & 18 & 0.29 & & \\
\hline
\end{tabular}

Note 4: $F 0.10(2,18)=2.78 ; F 0.05(2,18)=3.55 ; F 0.01(2,18)=6.01 ; * F$ ratio $>F 0.1 ; * * F 0.01>F$ ratio $>F 0.05 ; * * * F$ ratio $>F 0.01$; ADS, Adding dosage of sucrose; FT, Fermentation time; PV, pH value; SC, Shaking condition, respectively; e, error. 


\subsubsection{The Yield of Adenosine}

The adenosine yield of the fermented wheat DDGS was shown in Table 6. The highest mean yield of adenosine was $1.89 \pm 0.11 \mu \mathrm{mol} / \mathrm{g}$ dry matter. The optimum Levels of factors were ADS 1, FT 2, PV 2 and SC 2, they were named $1 \%$ adding dosage of the surcose, 15 days of the fermentation time, $7 \mathrm{of} \mathrm{pH}, 50 \mathrm{round} / \mathrm{min}$ of shaking condition, respectively. The $R$ value of various factors indicated that the fermentation time (15 days) was the highest among these factors. And the significant levels were shown in Table 7, the results were indicated that the adenosine content of the fermented wheat DDGS was significantly related to the fermentation time, shaking condition and $\mathrm{pH}$. The adding dosage of surcose exhibited little influence on the adenosine content. Further, the ADS 1, FT 2, PV 2 and SC 2 conditions were demonstrated, the mean adenosine content of the fermented wheat DDGS was reached to $1.93 \pm 0.21 \mu \mathrm{mol} / \mathrm{g}$ dry matter. Compared with the adenosine content of unfermented wheat DDGS $(0.18 \pm 0.02 \mu \mathrm{mol} / \mathrm{g}$ dry matter), the adenosine content was increased 10 folds by $P$. aemulans, under the optimum fermentation conditions of adenosine (ADOFC).

Table 6. $\mathrm{L}_{9}\left(3^{4}\right)$ orthogonal experiment results of adenosine content

\begin{tabular}{cccccc}
\hline $\begin{array}{c}\text { Experimental } \\
\text { group }\end{array}$ & ADS & FT & PV & SC & $\begin{array}{c}\text { Adenosine content } \\
(\mu \mathrm{mol} / \mathrm{g} \text { dry matter })\end{array}$ \\
\cline { 2 - 6 } & \multicolumn{5}{c}{ Level } \\
\hline 1 & 1 & 1 & 1 & 1 & $0.36 \pm 0.04$ \\
2 & 1 & 2 & 2 & 2 & $1.89 \pm 0.11$ \\
3 & 1 & 3 & 3 & 3 & $0.91 \pm 0.13$ \\
4 & 2 & 1 & 2 & 3 & $1.43 \pm 0.10$ \\
5 & 2 & 2 & 3 & 1 & $0.64 \pm 0.14$ \\
6 & 2 & 3 & 1 & 2 & $0.87 \pm 0.05$ \\
7 & 3 & 1 & 3 & 2 & $1.36 \pm 0.24$ \\
8 & 3 & 2 & 1 & 3 & $0.71 \pm 0.11$ \\
9 & 3 & 3 & 2 & 1 & $0.94 \pm 0.02$ \\
$\mathrm{I}_{\mathrm{j}}$ & 9.48 & 9.45 & 5.81 & 5.83 & \\
$\mathrm{II}_{\mathrm{j}}$ & 8.83 & 9.72 & 12.81 & 12.36 & \\
$\mathrm{III}_{\mathrm{j}}$ & 9.02 & 8.16 & 8.71 & 9.14 & \\
$R$ & 0.65 & 1.56 & 4.1 & 6.53 & \\
Optimum & 1 & 2 & 2 & 2 & \\
Level & 1 & & & & \\
\hline
\end{tabular}

Note 5: ADS, Adding dosage of sucrose; FT, Fermentation time; SC, Shaking condition, respectively. Mean values were mean of three determinations with standard deviation $( \pm) . \mathrm{I}_{\mathrm{j}}, \mathrm{II}_{\mathrm{j}}$, III $\mathrm{j}$, were the adenosine contents of level 1 , level 2 and level 3, respectively; $R$ means the maximum of $\mathrm{I}_{\mathrm{j}}, \mathrm{II}_{\mathrm{j}}$ and $\mathrm{III}_{\mathrm{j}}$ minus the minimum of $\mathrm{I}_{\mathrm{j}}$, $\mathrm{II}_{\mathrm{j}}$ and $\mathrm{III}_{\mathrm{j}}$, respectively.

Table 7. The variance analysis of $\mathrm{L}_{9}\left(3^{4}\right)$ orthogonal test of adenosine content

\begin{tabular}{cccccc}
\hline Factor & $\begin{array}{c}\text { Sum of square deviation } \\
(\mathrm{SS})\end{array}$ & $\begin{array}{c}\text { Degree of freedom } \\
(v)\end{array}$ & $\begin{array}{c}\text { Mean square } \\
(\mathrm{MS})\end{array}$ & $F$ ratio & Significance level \\
\hline ADS & 0.02 & 2 & 0.01 & 0.85 & \\
FT & 2.75 & 2 & 1.37 & 94.28 & $* * *$ \\
PV & 0.15 & 2 & 0.08 & 5.30 & $* *$ \\
SC & 2.37 & 2 & 1.18 & 81.26 & $* * *$ \\
e & 0.26 & 18 & 0.01 & & \\
\hline
\end{tabular}

Note 6: $F 0.10(2,18)=2.78 ; F 0.05(2,18)=3.55 ; F 0.01(2,18)=6.01 ; * F$ ratio $>F 0.1 ; * * F 0.01>F$ ratio $>F 0.05$; *** $F$ ratio $>F 0.01$; ADS, Adding dosage of sucrose; FT, Fermentation time; PV, pH value; SC, Shaking condition, respectively; e, error. 


\subsection{The Optimum Fermentation Condition of Polysaccharide, Polyphenol and Adenosine (PPAOFC)}

According to the results of orthogonal experiment, the optimum fermentation conditions of polysaccharide, polyphenol and adenosine were different. Therefore, it was necessary to discuss the optimum fermentation condition of polysaccharide, polyphenol and adenosine (PPAOFC). The polysaccharide contents of PSOFC $(32.68 \pm 3.24 \mathrm{mg} / \mathrm{g}$ dry matter), PPOFC $(9.76 \pm 0.68 \mathrm{mg} / \mathrm{g}$ dry matter $)$ and ADOFC (5.68 $\pm 0.8 \mathrm{mg} / \mathrm{g}$ dry matter) were shown in Figure $1 \mathrm{~A}$, by using Duncan's multiple range test, the polysaccharide content of PSOFC, was significantly higher than that of PPOFC and ADOFC. Further, polyphenol and adenosine contents of PSOFC, PPOFC and ADOFC were compared, the significant levels and contents were shown in Figure $1 \mathrm{~B}$ and $\mathrm{C}$. The polyphenol contents of PSOFC, PPOFC and ADOFC were $7.91 \pm 0.2,9.46 \pm 0.34$ and $7.99 \pm 0.58 \mathrm{mg} / \mathrm{g}$ dry matter, respectively. The adenosine contents of PSOFC, PPOFC and ADOFC were $1.36 \pm 0.24,0.81 \pm 0.11$ and $1.94 \pm .021 \mu \mathrm{mol} / \mathrm{g}$ dry matter, respectively. As the results, PSOFC was the optimum fermentation condition of polysaccharide, polyphenol and adenosine for producing polysaccharide, polyphenol and adenosine.

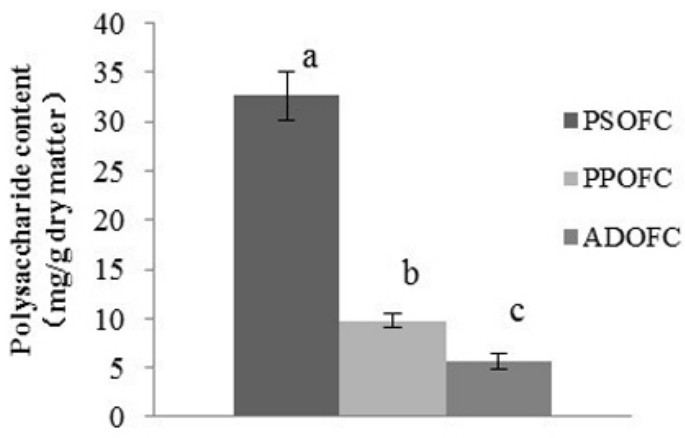

A

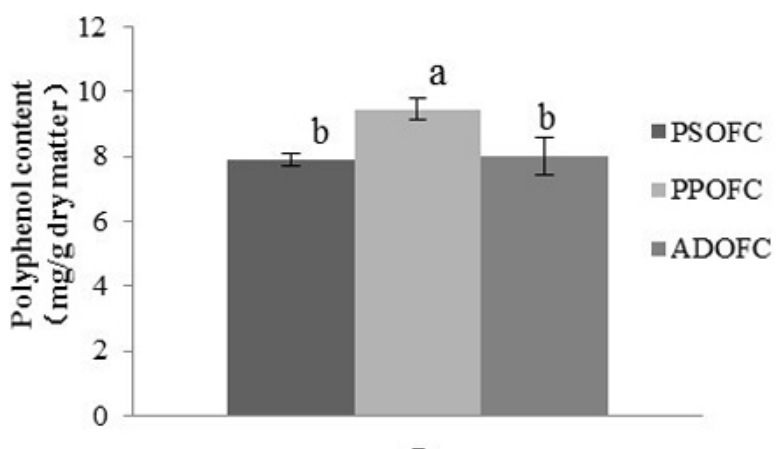

B

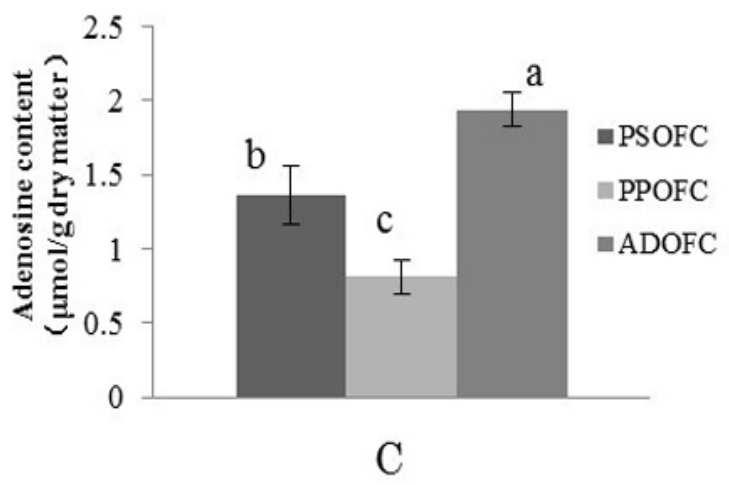

Figure 1. The optimum fermentation condition of polysaccharide, polyphenol and adenosine (PPAOFC) of wheat DDGS by Duncan's multiple range test

(A), (B) and (C) were the polysaccharide, polyphenol, adenosine content of three optimum fermentation conditions (PSOFC, PPOFC, ADOFC), respectively (a. b. c. $p<0.05$, Data were expressed as means \pm S.D. $n=3$ ).

\subsection{The Changes of Protein and Total Free Amino Acid Contents of Fermented Wheat DDGS under PPAOFC}

As shown in Figure 2, the protein content of the fermented wheat DDGS on PPAOFC and unfermented wheat DDGS, were $104.41 \pm 6.65$ and $67.86 \pm 5.42 \mathrm{mg} / \mathrm{g}$ dry matter, respectively. And the protein content was increased 1.5 folds under PPAOFC by P. aemulans. The total free amino acid content was shown in Figure 3. After the fermentation, the total amino acid was decreased $64 \%$ to $98.92 \pm 10.63 \mu \mathrm{mol} / \mathrm{g}$ dry matter. However, the total free amino acid content of unfermented wheat DDGS was $274.78 \pm 19.56 \mu \mathrm{mol} / \mathrm{g}$ dry matter, which was much higher than that of fermented wheat DDGS and other functional materials, such as the unfermented and fermented soybean residue (10.93 \pm 0.27 and $225.13 \pm 18.41 \mu \mathrm{mol} / \mathrm{g}$ dry matter) by Lentinus edodes (Shi et al., 2012). Based on the protein content of fermented wheat DDGS, it was considered that the decrease of free amino acid of unfermented wheat DDGS was utilized by P. aemulans to converted to protein. 


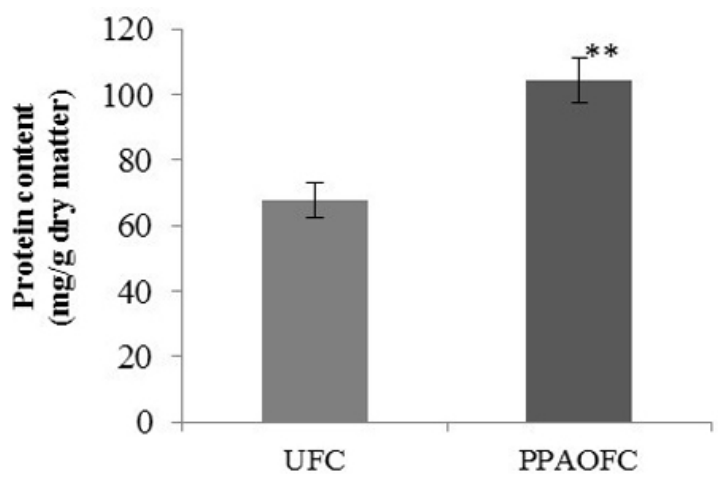

Figure 2. The protein contents of unfermented (UFC) and the optimum fermentation condition of polysaccharide, polyphenol and adenosine (PPAOFC)

Unfermented wheat DDGS was control. Data were expressed as means \pm S.D. $(\mathrm{n}=3) \stackrel{* *}{*} p<0.01$ in comparison with the control).

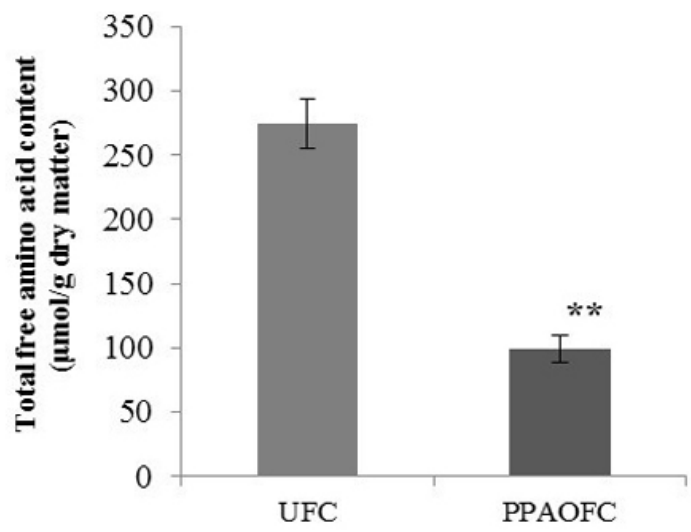

Figure 3. The total free amino acid contents of unfermented (UFC) and the optimum fermentation condition of polysaccharide, polyphenol and adenosine (PPAOFC)

Unfermented wheat DDGS was the control. Data were expressed as means \pm S.D. $(\mathrm{n}=3){ }^{* *} p<0.01$ in comparison with the control).

\subsection{The Cordycepin Content of Fermented Wheat DDGS under PPAOFC}

According to previous studies, the cordycepin content that contained in cordyceps sinensis was lower than that of other cordyceps fungi. And the content of natural cordyceps sinensis fruiting body was much higher than that of culture mycelium (Li et al., 2004; Sun, Ling, Lu, Zhang, \& Zhang, 2003). In this study, cordycepin has not been detected under PPAOFC. The optimum fermentation condition of cordycepin content by $P$. aemulans should be explored in the future.

\section{Conclusions}

The optimum fermentation condition of polysaccharide, polyphenol and adenosine (PPAOFC) was determined in this study, the fermentation condition were $3 \%$ adding dosage of the surcose, 10 days of the fermentation time, 8 of $\mathrm{pH}, 50 \mathrm{round} / \mathrm{min}$ of shaking condition, respectively. In the PPAOFC, the polysaccharide, polyphenol, adenosine content were increased 14, 6 and 10 folds comparing with the unfermented condition, and the content were $32.68 \pm 3.24 \mathrm{mg} / \mathrm{g}$ dry matter, $7.91 \pm 0.2 \mathrm{mg} / \mathrm{g}$ dry matter and $1.36 \pm 0.24 \mu \mathrm{mol} / \mathrm{g}$ dry matter, respectively. After the fermentation, the protein content was increased 1.5 folds, and reached to $104.41 \pm 6.65 \mathrm{mg} / \mathrm{g}$ dry matter. Therefore, based on the nutrient substance, the fermented wheat DDGS could be utilized as animal feed and food additives in further.

\section{References}

Bhanja, T., Kumari, A., \& Banerjee, R. (2008). Enrichment of phenolics and free radical scavenging property of wheat koji prepared with two filamentous fungi. Bioresource Technology, 100(11), 2861-2866. 
http://dx.doi.org/10.1016/j.biortech.2008.12.055

Chen, W. X., Zhang, W. Y., Shen, W. B., \& Wang, K. C. (2010). Effects of the acid polysaccharide fraction isolated from a cultivated Cordyceps sinensis on macrophages in vitro. Cellular Immunology, 264 (1), 67-74. http://dx.doi.org/10.1016/j.cellimm.2010.01.001

Corradetti, R., Conte, G. L., Moroni, F., Passani, M. B., \& Pepeu, G. (1984). Adenosine decreases aspartate and glutamate release from rat hippocampal slices. European Journal of Pharmacology, 104, 19-26. http://dx.doi.org/10.1016/0014-2999(84)90364-9

Cozannet, P., Primot, Y., Gady, C., Métayer, J. P., Lessire, M., Skiba, F., et al. (2010). Energy value of wheat distillers grains with solubles for growing pigs and adult sows. Canadian Journal of Animal Science, 88, 2382-2392. http://doi:10.2527/jas.2009-2510

Greter, A. M., Penner, G. B., Davis, E. C., \& Oba, M. (2008). Effect of replacing corn dry distillers grains' with triticale dry distillers'grains on lactation performance and plasma metabolites. Canadian Journal of Animal Science, 88, 129-132. http://doi:10.4141/CJAS07116

Ikeda, R., Nishimura, M., Sun, Y., Wada, M., \& Nakashima, K. (2008). Simple HPLC-UV determination of nucleosides and its application to the authentication of Cordyceps and its allies. Biomedical Chromatography, 22, 630-636. http://doi: 10.1002/bmc.980

Kumara, R., Negib, P. S., Singhc, B., Ilavazhagana, G., Bhargavaa, K., \& Sethya, N. K. (2011). Cordyceps sinensis promotes exercise endurance capacity of rats by activating skeletal muscle metabolic regulators. Journal of Ethnopharmacology, 136(1), 260-266. http://dx.doi.org/10.1016/j.jep.2011.04.040

Li, S. P., Li, P., Lai, C. M., Gong, Y. X., Kan, K. K. W., Dong, T. T. X., et al. (2004). Simultaneous determination of ergosterol, nucleosides and their bases from natural and cultured Cordyceps by pressurised liquid extraction and high-performance liquid chromatography. Journal of Chromatography, 1036, 239-243. http://doi:10.1016/j.chroma.2004.02.080

Li, S. P., Yang, F. Q., \& Tsim, K. W. K. (2006). Quality control of Cordyceps sinensis, a valued traditional Chinese medicine Journal of Pharmaceutical and Biomedical Analysis, 41, 1571-1584. http://doi: 10.1016/j.jpba.2006.01.046

Masuko, T., Minami, A., Iwasaki, N., Majima, T., Nishimaru, S., \& Lee, Y. C. (2005). Carbohydrate analysis by a phenol-sulfuric acid method in microplate format. Analytical Biochemistry, 339, 69-72. http://dx.doi.org/10.1016/j.ab.2004.12.001

Mau, J. L., Lin, H. C., \& Song, S. F. (2002). Antioxidant properties of several specialty mushrooms. Food Research International, 35, 519-526. http://dx.doi.org/10.1016/S0963-9969(01)00150-8

Penner, G. B., Yu, P., \& Christensen, D. A. (2009). Effect of replacing forage or concentrate with wet or dry distillers'grains on the productivity and chewing activity of dairy cattle. Animal Feed Science and Technology, 153(1-2), 1-10. http://dx.doi.org/10.1016/j.anifeedsci.2009.05.006

Pyoa, Y. H., Leeb, T. C., Logendrac, L., \& Rosen, R. T. (2004). Antioxidantactivity and phenoliccompounds of Swiss chard (Beta vulgaris subspecies cycla) extracts. Food Chemistry, 85(1), 19-26. http://dx.doi.org/10.1016/S0308-8146(03)00294-2

Russell, R., \& Paterson, M. (2008). Cordyceps- A traditional Chinese medicine and another fungal therapeutic biofactory? Phytochemistry, 69, 1469-1495. http://doi:10.1016/j.phytochem.2008.01.027

Shi, M., Yang, Y. N., Guan, D., Wang, Y. P., \& Zhang, Z. Y. (2012). Evaluation of Solid-State Fermentation by Ganoderma lucidum Using Soybean Curd Residue. Food and Bioprocess Technology. http://doi 10.1007/s11947-012-0857-y

Shi, M., Yang, Y. N., Li, Y. T., Wang., Y. P., \& Zhang, Z. Y. (2011). Optimum Condition of Ecologic Feed Fermentation by Pleurotus Ostreatus Using Soybean Curd Re sidue as Raw Materials International Journal of Biology, 3, 2-12. http://doi:10.5539/ijb.v3n4p2

Shi, M., Yang, Y. N., Wang, Q. H., Zhang, Y., Wang, Y. P., \& Zhang, Z. Y. (2012). Production of total polyphenol from fermented soybean curd residue by Lentinus edodes. International Journal of Food Science and Technology, 46(6), 1215-1221. http://doi:10.1111/j.1365-2621.2012.02961.x

Soong, Y. Y., \& Barlow, P. J. (2004). Antioxidant activity and phenolic content of selected fruit seeds. Food Chemistry, 88 (3), 411-417. http://doi: 10.1016/j.foodchem.2004.02.003 
Sun, Y. J., Ling, J. Y., Lu, P., Zhang H. X., \& Zhang, C. K. (2003). Determination of Cordycepin in Cordyceps kyushuensis by Capillary Electrophoresis and its Antitumour Activity. Chinese Chemical Letters, 14, 724-723. http://www.imm.ac.cn/journal/ccl.htmL

Widyaratne, G. P., \& Zijlstra, R. T. (2007). Nutritional value of wheat and corn distiller's dried grain with solubles: Digestibility and digestible contents of energy, amino acids and phosphorus, nutrient excretion and growth performance of grower-finisher pigs Canadian Journal of Animal Science, 87(1), 103-114. http://doi:10.4141/A05-070

Zhang, M., Cui, S. W., Cheung, P. C. K., \& Wang, Q. (2007). Antitumor polysaccharides from mushrooms: a review on their isolation process, structural characteristics and antitumor activity. Trends in Food Science \& Technology, 18 (1), 4-19. http://dx.doi.org/10.1016/j.tifs.2006.07.013

Zhang, Y. J., Sun, B. D., Zhang, S., Wang, M., Liu, X. Z., \& Gong, W. F. (2010). Mycobiotal investigation of natural Ophiocordyceps sinensis based on culture-dependent investigation. Mycosystema, 29(4), 518-527. http://journals.im.ac.cn/jwxtcn/ch/reader/view_abstract.aspx?file_no=10040518 